\title{
Studies on Different Temperature Humidity Index Models in Relation with Production Traits for Phule Triveni Cattle
}

\author{
Swapnali Uttamrao Rokade*, Dilip Kundalik Deokar, Harshavardhan Shahaji \\ Sonawane and Ghoshita Suryakant Hingonekar
}
${ }^{1}$ Department of Animal Husbandry and Dairy Science, College of Agriculture Dhule, Mahatma PhuleKrishiVidyapeeth, Rahuri, India

*Corresponding author

\section{A B S T R A C T}

\section{Keywords}

Phule Triveni, TMY, LL, DP, PMY, THI

Article Info

Accepted:

04 December 2020

Available Online:

10 January 2021
The data on production performance of Phule Triveni cattle maintained at Research cum Development Project on Cattle (RCDP), Mahatma Phule Krishi Vidyapeeth, Rahuri district, Ahmednagar, (M.H) were utilized for present study. The least squares means of total milk yield (kg), lactation length (days), dry period (days) and peak milk yield (kg) were estimated by considering the effects of period of calving, season of calving and lactation order as non-genetic factors. Then data were corrected for significant non genetic factor effect and effect of THI was estimated. The frequency distribution patterns for MMY according to THI were worked out. The overall least squares means for TMY, LL, DP and PMY are $2612.88 \pm 75.48 \mathrm{~kg}, 306.43 \pm 5.51$ days, $144.12 \pm 11.38$ days and 14.87 $\pm 0.30 \mathrm{~kg}$, respectively in Phule Triveni cattle. The THI had significant influence on production traits TMY, LL, PMY, indicating that the Phule Triveni cows were acclimitised to the local climate due to optimum feeding with sound management are provided. However, the THI had non-significant influence on trait DP. The overall observations reveals the result that THI 3 is the most suitable model of THI for Phule Triveni cattle.

\section{Introduction}

Increased pressure for intensified milk production and simultaneous rise in environmental temperature due to global warming has increased the thermal load on dairy animals. Elevated environmental temperature combined with high humidity causes discomfort and escalates the stress level in animals which is reflected in terms of reduced physiological and metabolic activities that results in reduced growth, drop in production and reproduction in farm animals. Heat stress is one of the most vital environmental stressor that has negative impact on milk yield, milk composition (fat $\%$, SNF\%, protein \% etc). Construction of Temperature Humidity Index (THI) by combining several climatological parameters like dry bulb, wet bulb temperature along with relative humidity to quantify the thermal stress is one of the best methods to assess heat 
stress on animals. Several research workers have reported that there exists a threshold THI value, above which the negative effects of heat stress is observed on animals. Mitigation strategies to combat heat stress includes selection of heat tolerant animals and their breeding, inclusion of heat tolerance as a trait while constructing selection index, providing balanced nutrition to the animals and implementation of good ventilation along with suitable cooling system in the farm (Behera et al., 2020).

\section{Materials and Methods}

The data of Phule Triveni cows maintained at Research Cum-Development Project on Cattle, M.P.K.V., Rahuri for a period from 2009 to 2019 (10 years) were collected for present investigation for following Traits:

a)Productive traits:1) Total lactation milk yield (kg),2) Lactation length (days),3) Dry period (days),4) Peak milk yield (kg).

To examine the Production traits, the research data was classified into 3 periods of calving viz. $\quad P_{1} \quad(2009-2011), \quad P_{2}(2012-2014), P_{3}$ (2015above);3 seasons of calving, viz. $S_{1}$ (Rainy) June- September, $\mathrm{S}_{2}$ (Winter) October-January and $\mathrm{S}_{3}$ (Summer) FebruaryMay; 5 order of lactation viz. $\mathrm{L}_{1}$ first lactation, $\mathrm{L}_{2}$ second lactation, $\mathrm{L}_{3}$ third lactation, $\mathrm{L}_{4}$ fourth lactation, $\mathrm{L}_{5}$ fifth lactation; 7 different THI values as THI1 in 6 Ranges THI11 (7174), THI12(74-77), THI13 (77-80), THI14 (80-83), THI15 (83-86), THI6 (86-89); THI2 in 5 Ranges THI21 (60-64), THI22 (64-68), THI23 (68-72), THI24 (72-76), THI25 (76 80);) ; THI3 in 5 Ranges THI31 (58-62), THI32 (62-66), THI33 (66-70), THI34 (7074), THI35 (74 -78);); THI4 in 4 Ranges THI41 (65-69), THI42 (69-73), THI43 (7377), THI44 (77-81); THI5 in 6 Ranges THI51 (72-75), THI52 (75-78), THI53 (78-81), THI54 (81-84), THI55 (84-87), THI56 (87 -
90); THI6 in 4 Ranges THI61 (65-70), THI62 (70-75), THI63 (75-80), THI64 (80-85); THI7 in 4 Ranges THI71 (65-69), THI72 (69-73), THI73 (73-77), THI74 (77-81)

The effects of non-genetic factors like period of calving, season of calving and parity were estimated by using least-square analysis as suggested by Harvey (1990). The model was used with the assumption that different components being fitted into the model were as linear, independent and additive. The model used was as follows:

\section{Model I}

$Y_{i j k l}=\mu+A_{i}+B_{j}+C_{k}+e_{i j k l}$

where $Y_{i j k l}$, observation of $1^{\text {th }}$ animal, $k^{\text {th }}$ parity, $j^{\text {th }}$ season of calving, $i^{\text {th }}$ period of calving; $\mu$ overall mean, $A_{i}$ fixed effect of $i^{\text {th }}$ period of calving ( 1 to 3 ), $B_{j}$ fixed effect of $j^{\text {th }}$ season of calving (1 to 3 ), $\mathrm{C}_{\mathrm{k}}$ fixed effect of $\mathrm{k}^{\text {th }}$ parity (1 to 5); $\mathrm{e}_{\mathrm{ijk} \mathrm{l}}$ random error $\sim$ NID $(0$, $\left.\sigma^{2} \mathrm{e}\right)$.

\section{Correction of data}

Whenever the effects found significant data were corrected and used for further analysis. The data on different production traits were corrected for the significant effects of period of calving, season of calving and lactation order. The corrected data were used to find out the effect of THI on production traits.

\section{Temperature humidity index models}

Seven reported THI models were used to compute temperature humidity index as follows:

\section{THI model reference}

THI1 $=[0.4 \times(\mathrm{Tdb}+\mathrm{Twb})] \times 1.8+32+15$ Thom (1959) 
THI2 $=(0.35 \times \mathrm{Tdb}+0.65 \times \mathrm{Twb}) \times 1.8+32$ Bianca (1962)

THI $3=(0.15 \times \mathrm{Tdb}+0.85 \times \mathrm{Twb}) \times 1.8+32$ Bianca (1962)

THI $4=(\mathrm{Tdb}+\mathrm{Twb}) \times 0.72+40.6 \mathrm{NRC}$ (1971)

THI5 $=(0.55 \times \mathrm{Tdb}+0.2 \times \mathrm{Tdp}) \times 1.8+32$ +17.5 NRC (1971)

THI6 $=(1.8 \times \mathrm{Tdb}+32)-(0.55-0.0055 \times$ $\mathrm{RH}) \times(1.8 \times \mathrm{Tdb}-26.8) \mathrm{NRC}(1971)$

THI7 $=(0.8 \times \mathrm{Tdb})+[(\mathrm{RH} / 100) \times(\mathrm{Tdb}-$ 14.4) ] + 46.4 (Mader et al., 2006)

Tdb: dry bulb temperature; Twb: wet bulb temperature; RH: relative humidity; Tdp: dew point temperature. Tdb, Twb and Tdp were measured in ${ }^{\circ} \mathrm{C}$ and $\mathrm{RH}$ was measured in $\%$.

Monthly THI will be computed using the environmental parameters and effect of THI was seen on traits under study by using following model.

\section{Model II}

$Y_{i j=} \mu+T_{H I}+e_{i j}$

$Y_{i j} \quad$ - Observation on $j^{\text {th }}$ parameters for $i^{\text {th }}$ THI value range

$\mu \quad$ - Overall mean

$\mathrm{THI}_{\mathrm{i}} \quad$ - Effect of $\mathrm{i}^{\text {th }} \mathrm{THI}$ value range

$\mathrm{e}_{\mathrm{ij}} \quad$ - Random error associated with NID $\left(0, \sigma^{2} \mathrm{e}\right)$

\section{Duncan's Multiple Range Test (DMRT)}

Duncan's Multiple Range Test as modified by Kramer (1957) was used to make pair wise comparison among the least square means with the use of inverse elements and root mean squares for error.

If the values:-

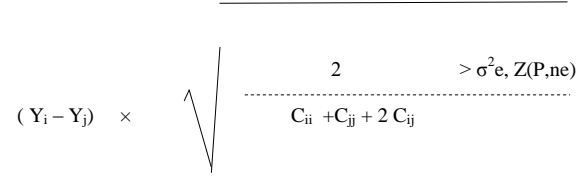

Where,

$\mathrm{Y}_{\mathrm{i}}-\mathrm{Y}_{\mathrm{j}}$ : Difference between two least squares means

$\mathrm{C}_{\mathrm{ii}}$ : Corresponding $\mathrm{i}^{\text {th }}$ diagonal elements of $\mathrm{C}$ matrix

$\mathrm{C}_{\mathrm{jj}}$ : Corresponding $\mathrm{j}^{\text {th }}$ diagonal elements of $\mathrm{C}$ matrix

$\mathrm{Z}$ ( $\mathrm{P}$, ne): Standardized range value in Duncan's table at the chosen level of probability for the error degrees of freedom.

$P$ Number of means involved in the comparison

$\sigma^{2} \mathrm{e}$ : Root mean squares for error

\section{Results and Discussion}

\section{Effect of THI on total milk yield}

The overall least squares mean of total milk yield in Phule Triveni cattle was 2442.83 $241.84 \mathrm{~kg}$. According to the above investigation the effect of THI1, THI2, THI3, THI4, THI6 and THI7 on total milk yield of Phule Triveni cattle was non-significant, except THI5. The differences in the total milk yield of Phule Triveni cows in THI 53 significantly higher than THI 52, THI 54 and THI 51.The differences in the total milk yield of Phule Triveni cows in THI 54 and THI 51, 
THI 56 and THI 55 were at par to each other. The maximum total milk yield was in THI 53 (4422.87 \pm 1369.86$)$ and minimum total milk yield was in THI $56(849.69 \pm 1248.88)$. This results was in accordance with GhaviHossein-
Zadeh et al., (2012), Gantner et al., (2012), H. Hammami et al., (2013), ForoughZareTamami et al., (2017), Behera et al., (2017), Habeeb (2020) in dairy cows (Table 1).

Table.1 Total milk yield (Kg), Lactation length (Days), Dry period (Days), Peak milk yield (Kg) as affected by THI in Phule Triveni cattle

\begin{tabular}{|c|c|c|c|c|c|}
\hline \multirow[t]{2}{*}{ Effect } & \multirow[t]{2}{*}{$\mathbf{N}$} & \multicolumn{4}{|c|}{ LEAST SQUARE MEANS } \\
\hline & & Total Milk Yield & $\begin{array}{l}\text { Lactation } \\
\text { Length }\end{array}$ & Dry period & Peak milk yield \\
\hline $\boldsymbol{\mu}$ & & $2442.83 \pm 241.84$ & $287.934 \pm 15.43$ & $156.49 \pm 32.41$ & $14.43 \pm 0.925$ \\
\hline THI11 & 4 & $2497.54 \pm 1368.43$ & $126.77 \pm 87.30$ & $253.57 \pm 183.40$ & $25.27^{\mathrm{a}} \pm 5.22$ \\
\hline THI12 & 22 & $617.48 \pm 1427.29$ & $106.85 \pm 91.06$ & $190.35 \pm 191.29$ & $16.41^{\mathrm{c}} \pm 5.47$ \\
\hline THI13 & 17 & $1184.26 \pm 1154.99$ & $307.24 \pm 73.68$ & $210.70 \pm 154.79$ & $16.62^{\mathrm{b}} \pm 4.41$ \\
\hline THI14 & 47 & $3184.02 \pm 918.89$ & $405.41 \pm 58.62$ & $34.11 \pm 123.15$ & $7.37^{\mathrm{f}} \pm 3.51$ \\
\hline THI15 & 39 & $3561.00 \pm 1015.19$ & $397.90 \pm 64.77$ & $90.36 \pm 136.05$ & $10.90^{\mathrm{d}} \pm 3.87$ \\
\hline THI16 & 8 & $3612.70 \pm 1308.82$ & $383.40 \pm 83.50$ & $159.86 \pm 175.41$ & $10.00^{\mathrm{e}} \pm 4.99$ \\
\hline THI21 & 6 & $1982.78 \pm 1111.20$ & $219.10 \pm 70.89$ & $231.35 \pm 148.92$ & $12.12^{\mathrm{c}} \pm 4.24$ \\
\hline THI22 & 24 & $2248.17 \pm 659.57$ & $374.43 \pm 42.08$ & $176.52 \pm 88.39$ & $10.89^{\mathrm{d}} \pm 2.51$ \\
\hline THI23 & 17 & $1609.74 \pm 552.93$ & $313.84 \pm 35.27$ & $183.82 \pm 74.10$ & $09.71^{\mathrm{e}} \pm 2.11$ \\
\hline THI24 & 56 & $2958.07 \pm 518.91$ & $276.06 \pm 33.10$ & $84.80 \pm 69.54$ & $18.00^{\mathrm{b}} \pm 1.98$ \\
\hline THI25 & 34 & $3415.40 \pm 679.78$ & $256.21 \pm 43.37$ & $105.97 \pm 91.10$ & $21.42^{\mathrm{a}} \pm 2.59$ \\
\hline THI31 & 8 & $2434.94 \pm 696.11$ & $343.77 \pm 44.41$ & $145.78 \pm 93.29$ & $13.82^{c} \pm 2.65$ \\
\hline THI32 & 26 & $2632.35 \pm 404.62$ & $243.94 \pm 25.81$ & $133.12 \pm 54.22$ & $17.05^{\mathrm{b}} \pm 1.54$ \\
\hline THI33 & 23 & $3015.61 \pm 429.66$ & $250.12 \pm 27.41$ & $155.75 \pm 57.58$ & $18.38^{\mathrm{a}} \pm 1.64$ \\
\hline THI34 & 58 & $1996.52 \pm 512.94$ & $286.11 \pm 32.72$ & $195.53 \pm 68.74$ & $1261^{\mathrm{d}} \pm 1.95$ \\
\hline THI35 & 22 & $2134.74 \pm 529.26$ & $315.70 \pm 33.76$ & $152.29 \pm 70.93$ & $10.29^{\mathrm{e}} \pm 2.02$ \\
\hline THI41 & 11 & $1768.03 \pm 769.77$ & $320.41 \pm 49.11$ & $35.28 \pm 103.16$ & $9.33 \pm 2.98$ \\
\hline THI42 & 31 & $2552.91 \pm 662.81$ & $343.14 \pm 42.28$ & $141.62 \pm 88.83$ & $11.9 \pm 2.54$ \\
\hline THI43 & 59 & $3363.24 \pm 648.47$ & $255.60 \pm 41.37$ & $194.43 \pm 86.91$ & $20.05 \pm 2.48$ \\
\hline THI44 & 36 & $2087.15 \pm 761.86$ & $232.56 \pm 48.60$ & $254.64 \pm 102.10$ & $16.43 \pm 2.91$ \\
\hline THI51 & 9 & $2241.15^{\mathrm{d}} \pm 726.00$ & $333.40^{\mathrm{b}} \pm 46.31$ & $119.15 \pm 97.30$ & $12.25^{\mathrm{d}} \pm 2.79$ \\
\hline THI52 & 22 & $3793.19^{b} \pm 877.24$ & $354.8^{\mathrm{a}} \pm 55.96$ & $164.62 \pm 117.57$ & $18.26^{\mathrm{a}} \pm 3.38$ \\
\hline THI53 & 18 & $4422.87^{\mathrm{a}} \pm 1369.86$ & $269.01^{\mathrm{e}} \pm 87.39$ & $127.19 \pm 183.59$ & $18.12^{\mathrm{b}} \pm 5.23$ \\
\hline THI54 & 49 & $2403.78^{c} \pm 765.25$ & $278.62^{c} \pm 48.82$ & $112.80 \pm 102.56$ & $16.87^{\mathrm{c}} \pm 2.93$ \\
\hline THI55 & 30 & $946.32^{\mathrm{e}} \pm 1024.34$ & $218.42^{f} \pm 65.35$ & $286.59 \pm 137.28$ & $11.02^{\mathrm{e}} \pm 3.93$ \\
\hline THI56 & 9 & $849.69^{f} \pm 1248.88$ & $273.31^{\mathrm{d}} \pm 79.68$ & $128.62 \pm 167.37$ & $10.06^{\mathrm{f}} \pm 4.78$ \\
\hline THI61 & 18 & $3620.07 \pm 670.49$ & $370.05 \pm 42.77$ & $168.38 \pm 89.86$ & $14.44 \pm 2.64$ \\
\hline THI62 & 27 & $2634.31 \pm 535.48$ & $312.81 \pm 34.16$ & $94.21 \pm 71.76$ & $11.72 \pm 2.04$ \\
\hline THI63 & 88 & $1742.77 \pm 538.60$ & $275.02 \pm 34.36$ & $177.97 \pm 72.18$ & $13.84 \pm 2.06$ \\
\hline THI64 & 4 & $1774.18 \pm 438.48$ & $193.84 \pm 53.49$ & $185.40 \pm 112.37$ & $17.72 \pm 3.20$ \\
\hline THI71 & 10 & $2876.40 \pm 1149.28$ & $309.58 \pm 73.32$ & $149.69 \pm 154.03$ & $14.80 \pm 4.39$ \\
\hline THI72 & 28 & $2138.40 \pm 663.11$ & $249.75 \pm 42.30$ & $166.36 \pm 88.87$ & $14.46 \pm 2.54$ \\
\hline THI73 & 48 & $1658.86 \pm 598.40$ & $264.95 \pm 38.17$ & $259.07 \pm 80.20$ & $12.74 \pm 2.29$ \\
\hline THI74 & 41 & $3097.67 \pm 1327.12$ & $327.44 \pm 84.67$ & $50.86 \pm 177.86$ & $15.72 \pm 5.09$ \\
\hline
\end{tabular}




\section{Effect of THI on lactation length}

The overall least squares mean of total milk yield in Phule Triveni cattle was 287.934 15.43days. According to the above investigation the effect of THI1, THI2, THI3, THI4, THI6 and THI7 were non significant on lactation length of Phule Triveni cattle, except THI5.The differences in THI5 within range 2 shows significantly higher than THI51, THI54, THI56, THI55, THI53 were at par to each other. The maximum lactation length was in THI 52 (354.8 \pm 55.96) and minimum lactation length was in THI 55 (218.42 \pm 65.35$)$. This results was in accordance with GhaviHossein-Zadeh et al., (2012), Gantner et al., (2012), Hammami et al., (2013), Forough Zare-Tamami et al., (2017), Behera et al., (2017), Habeeb,(2020) in dairy cows.

\section{Effect of THI on dry period}

The overall least squares mean of dry period

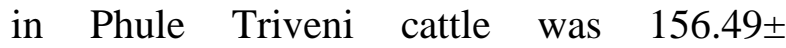
32.41days. According to the above investigation the effect of THI1, THI4, THI5, THI6 and THI7 on dry period of Phule Triveni cattle, was non-significant. This results was in accordance with GhaviHosseinZadeh et al., (2012), Gantner et al., (2012), Hammami et al., (2013), ForoughZareTamami et al., (2017) in dairy cows.

\section{Effect of THI on peak milk yield}

The overall least squares mean of peak milk yield in Phule Triveni cattle was 14.43 \pm $0.925 \mathrm{~kg}$.According to the above investigation the effect of THI1,THI2,THI3 and THI5 on peak milk yield of Phule Triveni cattle, was significant, except the effect of THI6, THI7. The differences in the dry period of cows in THI11 significantly higher than THI13, THI 12, THI 15 and THI 14. THI 25 significantly higher than THI24, THI21, THI22, THI23,
THI 33significantly higher than THI 32 and THI 31, THI 34 and THI 35.THI 52 significantly higher than THI53, THI54, THI51, THI55, THI56. The maximum peak milk yield was in THI $11(25.27 \pm 5.22 \mathrm{~kg})$ and minimum peak milk yield was in THI 14 $(7.37 \pm 3.51 \mathrm{~kg})$. This results was in accordance with Ghavi Hossein-Zadeh et al., (2012), Gantner et al., (2012), Behera et al., (2017) in dairy cows.

\section{References}

Behera R., Mandal A., Rai S., Karunakaran M. and Mondal M. (2020). Temperature Humidity Index and it's relationship with production traits of dairy cattle and buffaloes - Review. International Journal of Livestock Research 10(3):38-48.

Forough Zare-Tamami, HasanHafezian, Ghodrat Rahimi-Mianji, Rohullah Abdullahpour, and Mohsen Gholizadeh (2017). Effect of the temperaturehumidity index and lactation stage on milk production traits and somatic cell score of dairy cows in Iran. Songklanakarin J. Sci. Technol. 40 (2), 379-383.

Gantner, P. Mijic, S. Jovanovac, N. Raguz, T. Bobic\& K. Kuterovac (2012). Influence of temperature-humidity index (THI) on daily production of dairy cows in Mediterranean region in Croatia. Article in EAAP Scientific Series, January 2012. 131(1): 71-80.

GhaviHossein-Zadeh, N.,Mohit, A. and Azad, N. (2012). Effect of temperaturehumidity index on productive and reproductive performances of Iranian Holstein cows. Iranian Journal of Veterinary Research, Shiraz University, 2013, 14(2): 106-112.

Habeeb, A. A. (2020). Impact of climate change in relation to TemperatureHumidity Index on productive and 
reproductive efficiency of dairy cattle. Int J Vet Anim Med 3(1): 1-10.

H. Hammami ,J. Bormann , N. M'hamdi ,H. H. Montaldo and N. Gengler (2013). Evaluation of heat stress effects on production traits and somatic cell score of Holsteins in a temperate environment. J. Dairy Sci. 96: 1844-
1855.

Harvey W.R. (1990). Least-squares analysis of data with unequal subclass numbers. ARS H-4, U.S.D.A, Washington.

Kramer, C.V. (1957). Extension of multiple range test to group correlated adjusted mean. Biometrics, 13: 13-20.

\section{How to cite this article:}

Swapnali Uttamrao Rokade, Dilip Kundalik Deokar, Harshavardhan Shahaji Sonawane and Ghoshita Suryakant Hingonekar. 2021. Studies on Different Temperature Humidity Index Models in Relation with Production Traits for Phule Triveni Cattle. Int.J.Curr.Microbiol.App.Sci. 10(01): 141-146. doi: https://doi.org/10.20546/ijcmas.2021.1001.016 